\title{
Experimental transition probabilities in NII lines
}

\author{
S. Mar, C. Pérez, V.R. González, M.A. Gigosos, J.A. del Val ${ }^{1}$, I. de la Rosa, and J.A. Aparicio \\ Departamento de Optica, Facultad de Ciencias, Universidad de Valladolid, 47071 Valladolid, Spain \\ ${ }^{1}$ Permanent address: Departamento de Física Aplicada, Universidad de Salamanca, E. Politécnica Superior 05071 Avila, Spain
}

Received February 15; accepted April 11, 2000

\begin{abstract}
This work reports an extensive collection of 108 transition probabilities of NII lines in the visible spectral region, all of them measured in an emission experiment. Relative intensity measurements have been made on a pulsed discharge lamp and the absolute $A_{k i}$ values have been obtained by using the literature available data. Electron density and temperature range in this experiment from 0.2 to $1.110^{23} \mathrm{~m}^{-3}$ and from 17000 to $29000 \mathrm{~K}$ respectively. The first one has been simultaneously determined from two-wavelength interferometry and from the Stark broadening of HeI $471.3 \mathrm{~nm}$, the second from Boltzmann-plot of NII lines and from NII/NI intensities ratios. The results are compared with the recent available literature.
\end{abstract}

Key words: atomic data — line: profile — methods: laboratory

\section{Introduction}

Nitrogen is among the most abundant elements in the universe. For the estimation of stellar chemical abundances the determination of radiative transition probabilities is of primary interest. Knowledge of the spectrum of singly ionised nitrogen is clearly required for the understanding of the associated plasmas. Moreover, it is frequently used in laboratory studies and in industrial applications. Although during the last decade, much theoretical effort has been devoted to advanced atomic structure calculation which provided such radiation data for NII (part of the Opacity Project), some accurate experimental data are still required (a) to establish with confidence the uncertainties of advanced calculations and (b) to settle especially the question to what degree $L S$ coupling is applicable for the individual line strengths in this spectrum. According to Wiese et al. (1996) there is a lack of experimental data which are accurate enough to sensitively test

Send offprint requests to: S. Mar the calculated results. Recently Musielok et al. 1996, have reported $A_{k i}$ values for a fairly large number of lines (52) of the $3 \mathrm{~s}-3 \mathrm{p}$ and $3 \mathrm{p}-3 \mathrm{~d}$ transition arrays of NII with a wall-stabilized arc source. One of the aims of the present work is just to provide in only one experiment a great amount of data. These will be compared with the most recent literature. Furthermore, this experiment gives $A_{k i}$ values for 13 NII spectral lines not collected in previous works, at least to the authors's knowledge.

All the results were obtained from measurements performed in a linear discharge lamp, where a mixture of helium and nitrogen was prepared so that self-absorption effects were negligible. The plasma source employed provides not only all kind of interferometric and spectroscopic registers with great reproducibility in different discharges, but also makes it possible in a broad range of electron density and temperature values. This allows us to acquire some reliable spectra for weak or non-isolated lines, otherwise very difficult to obtain.

In the present work absolute $A_{k i}$ values have been obtained from relative intensity measurements taking as reference values the $A_{k i}$ data available in the last NIST critical compilation (Wiese et al. 1996). In this way, we have determined NII excitation temperatures from Boltzmann-plots, and also temperatures given from NII/NI intensities ratios. The very good agreement between the two methods suggests that the plasma is well described by a partial local thermodynamic equilibrium (pLTE) model. The absence of self-absorption and the spectral calibration have been very carefully taken into account. The number of measurements (15) performed for each line along the plasma life, and its very controlled features, allows us to obtain a very good $A_{k i}$ value by the mean value, and its uncertainty by the standard deviation (usually around 10\%).

\section{Experimental arrangement}

The experimental set-up (shown in Fig. 1) and the methods have already been described in Gigosos et al. (1994), 
Aparicio et al. $(1997,1998)$. Here we summarize the specific details corresponding to the present experiment.

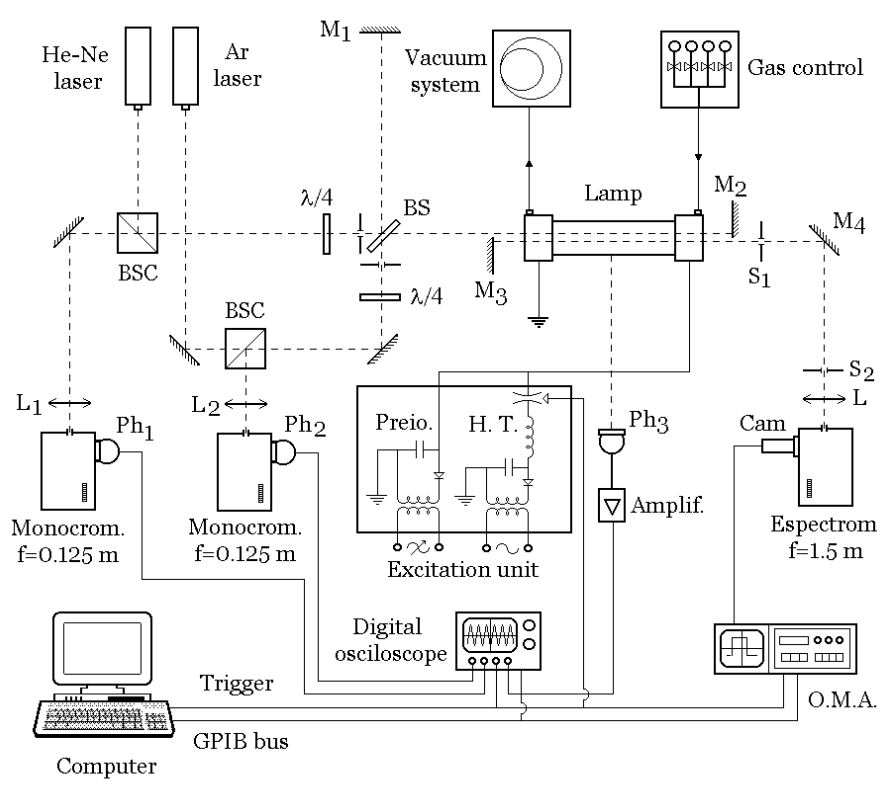

Fig. 1. Experimental set-up

The source of plasma consists of a cylindrical tube of Pyrex glass with $175 \mathrm{~mm}$ in length and $19 \mathrm{~mm}$ in interior diameter. The lamp has been designed to avoid sputtering as much as possible. The plasmas were created by discharging a capacitor bank of $20 \mu \mathrm{F}$ charged up to $7.5 \mathrm{kV}$. During the whole experiment the lamp was working with a continuous flow of a mixture of helium and nitrogen, at a rate of $10 \mathrm{~cm}^{3} / \mathrm{min}$ and $5 \mathrm{~cm}^{3} / \mathrm{min}$ respectively and a global pressure of $1340 \mathrm{~Pa}$. In these conditions, the NII emission lasts around $200 \mu \mathrm{s}$. The gas was pre-ionised in order to obtain the best discharge reliability. Spectroscopic and interferometric end-on measurements have been made simultaneously through the plasma life, and have been taken $2 \mathrm{~mm}$ off the lamp axis, and from symmetrical positions referred to it. The high axial homogeneity and the very good cylindrical symmetry of electron density and temperature in this lamp allows this (del Val et al. 1998).

According to Fig. 1, the lamp is placed in one of the arms of a Twyman-Green interferometer simultaneously illuminated with an argon ion laser (488.0 nm) and by an He-Ne laser $(632.8 \mathrm{~nm})$. The spectroscopic beam is directed (3 mm pinholes $\mathrm{S} 1, \mathrm{~S} 2$, separated $1.5 \mathrm{~m}$ ) and focused (cylindrical lens $\mathrm{L}$ with $150 \mathrm{~mm}$ focal length) onto the entrance slit of a Jobin-Yvon spectrometer (1.5 $\mathrm{m}$ focal length, 1200 lines/mm holographic grating), equipped with an optical multichannel analyser (OMA). This OMA has a detector array which is divided into 512 channels (EG\&G 1455R-512-HQ). The dispersion was $12.59 \mathrm{pm} /$ channel at $589.0 \mathrm{~nm}$ in first order of diffraction. The spectrometer was very carefully calibrated in wavelength as well as in intensity (Aparicio et al. 1997). Time exposures for the spectra were $5 \mu \mathrm{s}$. Mirror M 3 , placed behind the plasma column, was used to measure the optical depth and to detect possible self-absorption effects on each line profile. This can be done by comparing the spectra taken with and without the light reflected by this mirror.

\section{Measurements and plasma diagnostics}

The experiment consists of end-on measurements of the NII lines emitted by the plasma in the region $380-700 \mathrm{~nm}$, and also the NI lines 742.36, 744.23 and $746.83 \mathrm{~nm}$. Each spectral interval has been recorded at 15 different instants of the plasma lifetime. For each instant, we have made six runs, three of them with the mirror M 3 and the other three ones without it, in order to test for self-absorption in all measurements. The averages of the 3 registers made without mirror M 3 differed from the measured spectra less than $4 \%$, which indicates the great repeatability of this plasma source. By comparing the average of registers with the mirror with the average of the registers without it and using the algorithms described in (González 1999) self-absorption only appeared in less than $2 \%$ of the whole spectral profiles. Even more, in less than $10 \%$ of these cases, the original profiles which can be reconstructed had peak intensity greater than 1.2 times that measured without mirror M 3. In these cases, the profile was rejected for further calculations. An example of a spectrum recorded with several NII lines at $50 \mu$ s of the plasma life is shown in Fig. 2.

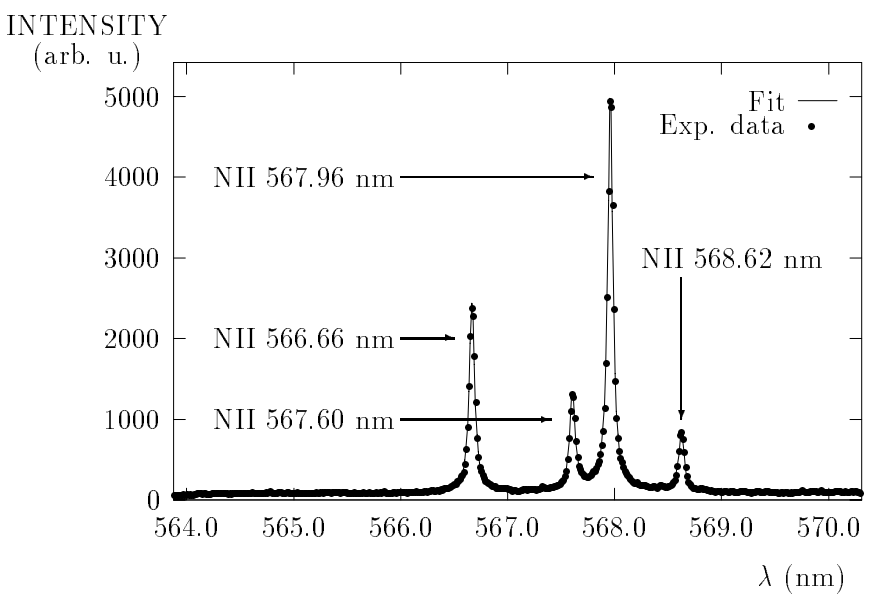

Fig. 2. An example of experimental spectrum showing several NII lines at the instant $50 \mu$ s of the plasma lifetime

It has also been possible to make measurements of the HeI $471.3 \mathrm{~nm}$ profiles, whose well-known Stark broadening has allowed us to determine the electron density spectroscopically. All the lines here considered were registered in first order of diffraction of the spectrometer, the most efficient. As a whole around 10000 discharges were made. 
In relation to interferometric registers, 450 interferograms for both wavelengths were taken at the beginning, in the middle and at the end of the whole experiment. Besides, at regular intervals of 1.5 hours, 15 interferograms were registered, all of them $500 \mu$ s long. They have been used to determine the electron density evolution curve and to detect possible drifts in such a long experiment. When comparing the different curves, differences were always lower than $5 \%$, which shows that no significant drifts occurred. This has also been shown when comparing temperature curves obtained from different groups of lines by means of Boltzmann-plots, each group corresponding to regular time intervals around 2 hours within the whole experiment. In fact, differences between temperature curves are also less than 5\%. Anyway we have taken in each case for further calculations its corresponding temperature and density curve.

After dividing the spectra by the spectrometer transmittance functions, all the spectra were fitted to sums of Lorentzian functions plus a luminous background with a linear dependence, as explained in reference (Gigosos et al. 1994). Differences between the experimental spectra and the fits were usually lower than $1 \%$ (see Fig. 2). This fitting algorithm allows to determine simultaneously the center, asymmetry, linewidth and area of each profile.

Figure 3 shows the electron density $N_{\mathrm{e}}$, determined interferometrically and spectroscopically. As it is shown in this figure, very good agreement between both methods is observed. Uncertainty in this plasma parameter is lower than $10 \%$.

$N_{e}$

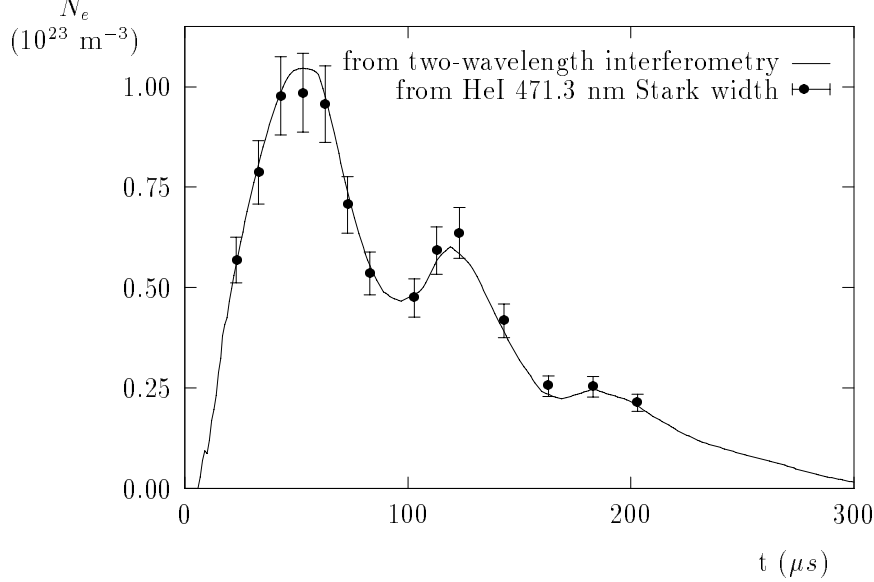

Fig. 3. Comparison between interferometric and spectroscopic electron density values. The uncertainty for this plasma parameter are below $10 \%$

In collision-dominated plasmas like the one generated in this experiment, it is a common hypothesis to assume that excitation temperature, Saha temperature and kinetic electron temperature take similar values (Van der Mullen 1990). In this work excitation temperature has been calculated from NII Boltzmann-plots. As Fig. 4 shows, these plots involve NII lines whose upper energy levels cover a very broad range (from 20.64 to $30.36 \mathrm{eV}$ ). Here, for temperature determination, we introduce a fairly large number of lines, that is, of $A_{k i}$ values taken from literature (the last data tabulated by NIST), which in fact will determine the absolute scale of this work $A_{k i}$ data. In this way, the accuracy of this work results comes both from the great number of literature collected data as the great number of measurements taken into account in the temperature calculation. Additional determination of temperature was obtained from the NII/NI intensities ratio by combining different NII and the NI measured lines. The statistical error of temperature calculated from Boltzmann-plot is less than $5 \%$ (with the exception of the three last instants of plasma life, which is $7 \%$ ). In the case of the temperature calculated from the intensity ratios this error does not exceed $3 \%$. When combining intensities of consecutive species to calculate temperatures, total LTE is assumed and the measured electron density is used. As it can be seen in Fig. 5, the two methods employed in this experiment give rise to temperatures which cannot be distinguished into a very reasonable error band around $10 \%$. Therefore, the assumption of a partial LTE model in the NII energy levels range considered can be perfectly made.

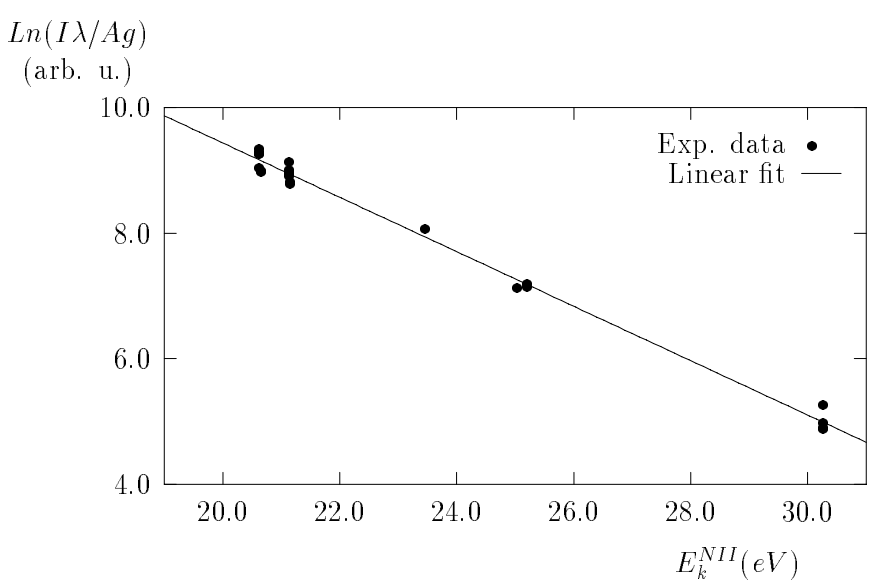

Fig. 4. An example of NII Boltzmann-plot corresponding to the plasmalife instant $50 \mu \mathrm{s}$. The good point distribution along the straight line shows that excitation temperature follows the Boltzmann law for these energy levels

\section{Results and conclusions}

Table 1 summarizes this work result, including the ratios with the literature collected values.

The uncertainty for each $A_{k i}$ value of this experiment which can be estimated by the standard deviation that shows the different 15 experimental values for each line, is showed in percentages. Although with a clear dependence 


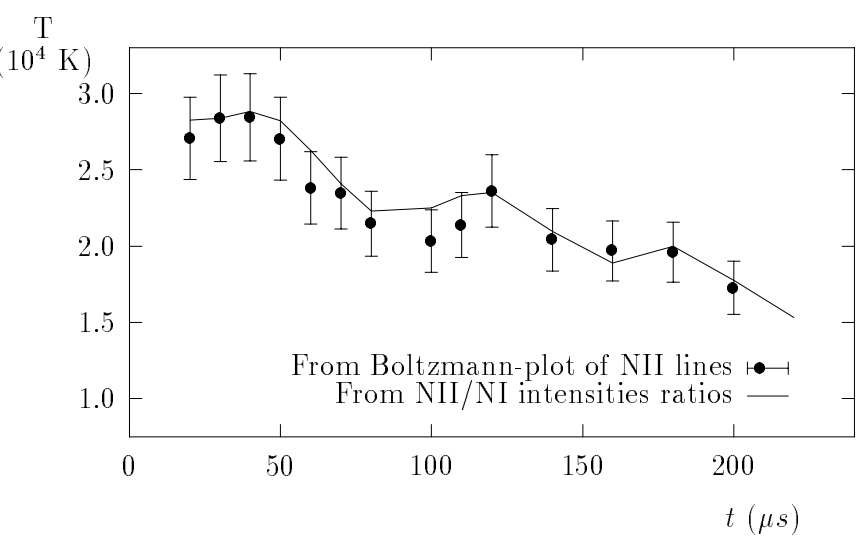

Fig. 5. NII excitation temperature evolution obtained from Boltzmann-plot and temperature curve obtained from NII/NI intensities ratio assuming total LTE. Although the statistical errors are below $5 \%$ in both methods, we give error bars up to $10 \%$ in order to include also the uncertainties coming from the set of $A_{k i}$ data taken as reference from NIST critical compilation

on the line, usually uncertainties in this work are around $10 \%$. For instance, Fig. 6 shows the different $A_{k i}$-values measured for two NII measured lines.

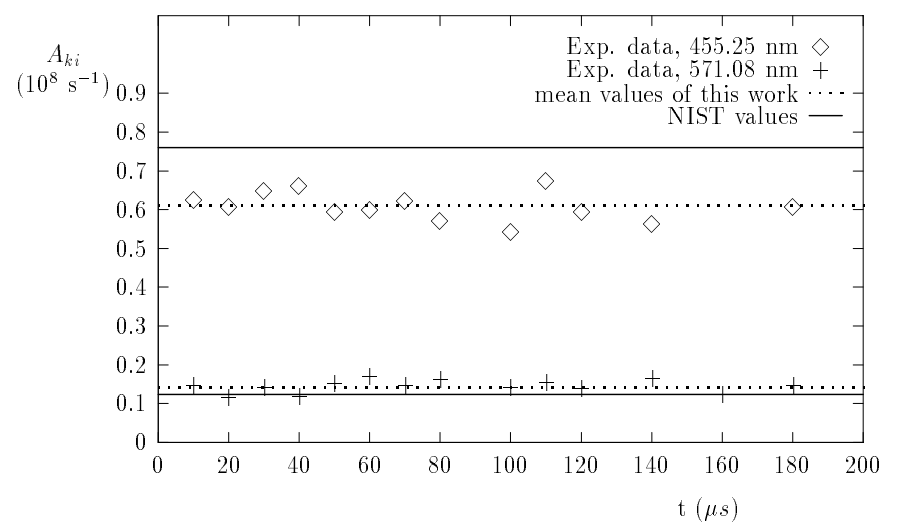

Fig. 6. An example of $A_{k i}$ data of this work versus time of the plasma life for two NII lines. No trends are observed. The data of NII $571.08 \mathrm{~nm}$ line are in good agreement within $10 \%$ uncertainties with the NIST value compiled by Wiese et al. 1996 (with 3\% accuracy). In the case of NII $455.25 \mathrm{~nm}$ line this work data (also with uncertainty of $10 \%$ ) show differences around $20 \%$ with available NIST value. This can be explained taking into account that NIST data base value is within $30 \%$ accuracy in this case

Figure 7 shows the relative differences between the NIST values taken from literature as reference to determine NII excitation temperature from Boltzmann-plots, and this work for each line, as a function of wavelength. As can be seen, almost $80 \%$ of the data show differences below $15 \%$. Usually NIST critical compilation assigned uncertainties around $10 \%$ to their values (in some cases around $30 \%$ ). Taking into account this uncertainty and the sta- tistical uncertainties assigned to each line in this work, the agreement is good. Also, Fig. 7 shows that there is no systematic trends in this experiment with wavelength, which gives an idea of the good spectral intensity calibration performed.

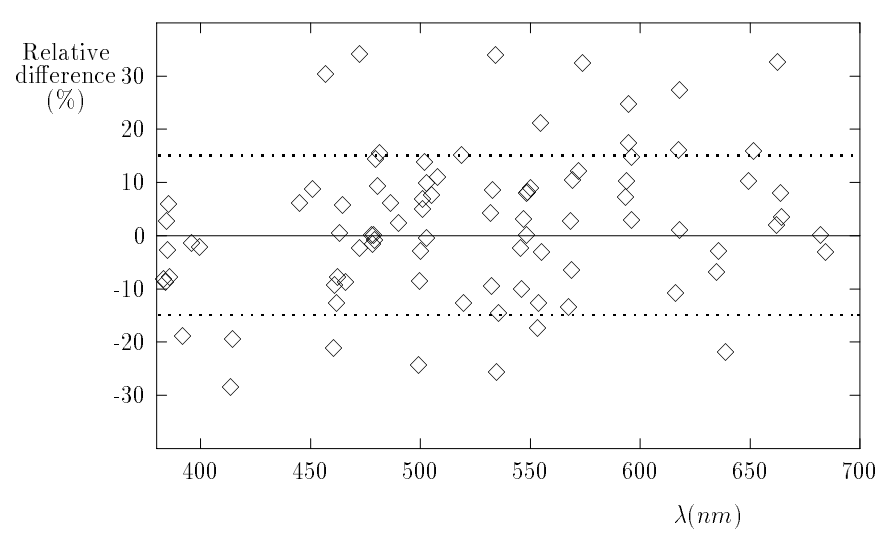

Fig. 7. Relative differences between this work $A_{k i}$ values and NIST tabulated ones, taken as reference, versus $\lambda$. No trends are detected and $77 \%$ of the data differ less than $15 \%$

As to the other literature collected data, the agreement is also good. The uncertainties of Musielok et al. work are also around $10 \%$, while the differences with theoretical values reported by Lavin et al. (1999) working with a Relativistic Quantum Defect Orbital (RQDO) method with explicit polarization correction are also within a $10 \%$ error band. As can be seen in the table, the ratios between this work values and those of Musielok et al. tend to be systematically different within some multiplets. Greater in the ${ }^{3} \mathrm{P}-{ }^{3} \mathrm{D}^{0}$ multiplet of the $3 \mathrm{p}-3 \mathrm{~d}$ transitions, and lower in the ${ }^{3} \mathrm{P}^{0}-{ }^{3} \mathrm{P}$ multiplet of the $3 \mathrm{~s}-3 \mathrm{p}$ transitions. These tendencies are not so clear in ratios with NIST data. Perhaps differences could be partially explained by the different method used by Musielok et al. to put their measured line data on an absolute basis. Anyway, the very careful spectral calibration used in this work excludes systematic errors due to wavelength dependencies.

The 7 values quoted with * in the column Tw/NIST need a special comment. Although they have been obtained from NIST Standard Reference Database 61 (1995), with the following reference: Fuhr J. \& Wiese W.L. "Atomic Transition Probabilities" in the CRC Handbook of Chemistry and Physics, chapter 10, (ed.) D.R. Lide (1995), they do not appear reflected in the Wiese et al. (1996) critical compilation. Besides NIST Database has assigned $30 \%$ uncertainties to these 7 lines. So they have not been used in the Boltzmann-plot temperature calculations in the present work. Their results show the greatest discrepancies. In the case of NII $405.69 \mathrm{~nm}$ line, this work result differ by a factor greater than 8 . Perhaps an edition mistake in one order of magnitude could explain this. 
As conclusion the main advantages of this experiment are the following:

a) About the $75 \%$ of the 95 spectral lines, whose data can be compared, agree both with the recent theoretical and experimental available data, assuming error bands around $10 \%$ in the considered works;

b) This work shows the coherence of a unique emission experiment, very carefully performed and with a good plasma diagnostics, which furnishes a great number of data for each line, and that for many lines;

c) Finally, this experiment improves the knowledge of $A_{k i}$-values for 13 new lines where we have not found previous references.

Acknowledgements. We thank S. González for his work in the experimental device. the Dirección General de Investigación Científica y Técnica (Ministerio de Educación y Ciencia) of Spain for its financial support under Contract No. PB-98-0356. and also the Consejería de Educación y Cultura de la Junta de Castilla y León (VA23-99). Dr. J.A. Aparicio wants to express his personal acknowledgement to the Organización Nacional de Ciegos de Espana (ONCE) for its help.

\section{References}

Aparicio J.A., Gigosos M.A., Mar S., 1997, J. Phys. B 30, 3141 Aparicio J.A., Gigosos M.A., González V.R., Pérez C., de la Rosa I., Mar S., 1998, J. Phys. B 31, 1029

del Val J.A., Mar S., Gigosos M.A., de la Rosa I., Pérez C., González V., 1998, Jpn. J. Appl. Phys. 37, 4177

Gigosos M.A., Mar S., Pérez C., de la Rosa I., 1994, Phys. Rev. E 49, 1575

González V.R., 1999, Ph.D. Thesis, Universidad de Valladolid Lavín C., Olalla E., Martín I., 1999 (private communication) Musielok J., Bridges J.M., Djurović S., Wiese W.L., 1996, Phys. Rev. A 53, 3122

Van der Mullen J.A.M., 1990, Phys. Rep. 191, 109

Wiese W.L., Fuhr J.R., Deters T.M., 1996, J. Phys. Chem. Ref. Data, Monograph 7. AIP, New York 
Table 1. $A_{k i}$-values from this work arranged by wavelength. All values must be multiplied by $10^{8} \mathrm{~s}^{-1}$, and uncertainties $\sigma$ are given in percentage. In the last three columns appear ratios between this work results Tw, and the available literature: NIST tabulated data by Wiese et al. (1996), Experimental data of Musielok et al. (1996) and theoretical calculations by RQDO treatment of Lavín et al., private communication (1999)

\begin{tabular}{|c|c|c|c|c|c|c|c|c|}
\hline $\begin{array}{l}\lambda \\
(\mathrm{nm})\end{array}$ & Transition & Multiplet & $J_{i}-J_{k}$ & $\begin{array}{l}A_{k i} \\
\text { This work }\end{array}$ & $\begin{array}{l}\sigma \\
(\%)\end{array}$ & $\begin{array}{l}T w / N I S T \\
\text { ratio }\end{array}$ & $\begin{array}{l}\text { Tw/Musielok } \\
\text { ratio }\end{array}$ & $\begin{array}{l}T w / R Q D O \\
\text { ratio }\end{array}$ \\
\hline 382.98 & $3 p-4 s$ & ${ }^{3} \mathrm{P}-{ }^{3} \mathrm{P}^{0}$ & $1-2$ & 0.223 & 16 & 0.92 & & \\
\hline 383.84 & $3 p-4 s$ & ${ }^{3} \mathrm{P}-{ }^{3} \mathrm{P}^{0}$ & $2-2$ & 0.639 & 6 & 0.92 & & \\
\hline 384.22 & $3 p-4 s$ & ${ }^{3} \mathrm{P}-{ }^{3} \mathrm{P}^{0}$ & $0-1$ & 0.314 & 11 & 1.03 & & \\
\hline 384.74 & $3 p-4 s$ & ${ }^{3} \mathrm{P}-{ }^{3} \mathrm{P}^{0}$ & $1-1$ & 0.216 & 12 & 0.97 & & \\
\hline 385.51 & $3 p-4 s$ & ${ }^{3} \mathrm{P}-{ }^{3} \mathrm{P}^{0}$ & $1-0$ & 0.935 & 20 & 1.06 & & \\
\hline 385.61 & $3 p-4 s$ & ${ }^{3} \mathrm{P}-{ }^{3} \mathrm{P}^{0}$ & $2-1$ & 0.343 & 7 & 0.93 & & \\
\hline 391.90 & $3 p-3 d$ & ${ }^{1} \mathrm{P}-{ }^{1} \mathrm{P}^{0}$ & $1-1$ & 0.559 & 10 & 0.83 & & 0.73 \\
\hline 395.59 & $3 s-3 p$ & ${ }^{3} \mathrm{P}^{0}-{ }^{1} \mathrm{D}$ & $1-2$ & 0.129 & 11 & 0.99 & 0.97 & \\
\hline 399.50 & $3 s-3 p$ & ${ }^{1} \mathrm{P}^{0}-{ }^{1} \mathrm{D}$ & $1-2$ & 1.320 & 11 & 0.98 & & 1.01 \\
\hline 402.61 & $3 d-4 f$ & ${ }^{3} F^{0}-G(9 / 2)$ & $3-4$ & 0.672 & 15 & $0.75^{*}$ & & \\
\hline 403.51 & $3 d-4 f$ & ${ }^{3} \mathrm{~F}^{0}-\mathrm{G}(7 / 2)$ & $2-3$ & 1.300 & 7 & & & \\
\hline 404.13 & $3 d-4 f$ & ${ }^{3} \mathrm{~F}^{0}-\mathrm{G}(9 / 2)$ & $4-5$ & 2.080 & 10 & $0.79^{*}$ & & \\
\hline 404.35 & $3 d-4 f$ & ${ }^{3} \mathrm{~F}^{0}-\mathrm{G}(7 / 2)$ & $3-4$ & 1.250 & 25 & $0.51^{*}$ & & \\
\hline 404.48 & $3 d-4 f$ & ${ }^{3} \mathrm{~F}^{0}-\mathrm{G}(7 / 2)$ & $3-3$ & 0.214 & 39 & & & \\
\hline 405.69 & $3 \mathrm{~d}-4 \mathrm{f}$ & ${ }^{3} \mathrm{~F}^{0}-\mathrm{G}(7 / 2)$ & $4-4$ & 0.199 & 20 & $0.12^{*}$ & & \\
\hline 407.30 & $3 d-4 f$ & ${ }^{3} \mathrm{~F}^{0}-\mathrm{F}(7 / 2)$ & $2-3$ & 0.499 & 19 & & & \\
\hline 407.69 & $3 d-4 f$ & ${ }^{3} \mathrm{~F}^{0}-\mathrm{F}(5 / 2)$ & $2-2$ & 0.080 & 42 & & & \\
\hline 408.23 & $3 d-4 f$ & ${ }^{3} \mathrm{~F}^{0}-\mathrm{F}(7 / 2)$ & $3-4$ & 0.335 & 16 & & & \\
\hline 413.18 & $3 d-4 f$ & ${ }^{1} \mathrm{D}^{0}-\mathrm{G}(7 / 2)$ & $2-3$ & 0.204 & 13 & & & \\
\hline 413.37 & $3 s-3 p$ & ${ }^{5} \mathrm{P}-{ }^{5} \mathrm{~S}^{0}$ & $2-2$ & 0.398 & 11 & 0.75 & & \\
\hline 414.58 & $3 s-3 p$ & ${ }^{5} \mathrm{P}-{ }^{5} \mathrm{~S}^{0}$ & $3-2$ & 0.605 & 15 & 0.82 & & \\
\hline 417.16 & $3 d-4 f$ & ${ }^{1} \mathrm{D}^{0}-\mathrm{F}(7 / 2)$ & $2-3$ & 0.448 & 11 & & & \\
\hline 417.36 & $3 d-4 f$ & ${ }^{3} \mathrm{D}^{0}-\mathrm{D}(5 / 2)$ & $2-2$ & 0.120 & 30 & & & \\
\hline 417.62 & $3 \mathrm{~d}-4 \mathrm{f}$ & ${ }^{1} \mathrm{D}^{0}-\mathrm{F}(5 / 2)$ & $2-3$ & 1.130 & 19 & $0.52^{*}$ & & \\
\hline 417.97 & $3 d-4 f$ & ${ }^{3} \mathrm{D}^{0}-\mathrm{D}(5 / 2)$ & $3-3$ & 0.470 & 23 & & & \\
\hline 441.71 & $3 d-4 f$ & ${ }^{3} \mathrm{P}^{0}-\mathrm{D}(3 / 2)$ & $2-2$ & 0.233 & 14 & & & \\
\hline 442.72 & $3 d-4 f$ & ${ }^{3} \mathrm{P}^{0}-\mathrm{D}(3 / 2)$ & $1-2$ & 0.568 & 50 & & & \\
\hline 444.20 & $3 d-4 f$ & ${ }^{3} \mathrm{P}^{0}-\mathrm{D}(5 / 2)$ & $1-2$ & 0.695 & 16 & & & \\
\hline 444.70 & $3 p-3 d$ & ${ }^{3} \mathrm{D}-{ }^{3} \mathrm{D}^{0}$ & $1-2$ & 1.210 & 9 & 1.06 & & 0.93 \\
\hline 450.76 & $3 p-3 d$ & ${ }^{3} \mathrm{D}-{ }^{3} \mathrm{P}^{0}$ & $3-2$ & 0.109 & 6 & 1.09 & & \\
\hline 453.04 & $3 d-4 f$ & ${ }^{1} \mathrm{~F}^{0}-\mathrm{G}(9 / 2)$ & $3-4$ & 1.450 & 20 & $0.86^{*}$ & & \\
\hline 455.25 & $3 d-4 f$ & ${ }^{1} \mathrm{~F}^{0}-\mathrm{G}(7 / 2)$ & $3-4$ & 0.611 & 9 & $0.80^{*}$ & & \\
\hline 456.48 & $3 p-3 d$ & ${ }^{1} \mathrm{P}-{ }^{3} \mathrm{~F}^{0}$ & $1-2$ & 0.019 & 16 & 1.36 & & \\
\hline 460.15 & $3 s-3 p$ & ${ }^{3} \mathrm{P}^{0}-{ }^{3} \mathrm{P}$ & $1-2$ & 0.190 & 9 & 0.81 & 0.69 & 0.86 \\
\hline 460.72 & $3 s-3 p$ & ${ }^{3} \mathrm{P}^{0}-{ }^{3} \mathrm{P}$ & $0-1$ & 0.297 & 8 & 0.91 & 0.76 & 0.95 \\
\hline 461.39 & $3 s-3 p$ & ${ }^{3} \mathrm{P}^{0}-{ }^{3} \mathrm{P}$ & $1-1$ & 0.199 & 4 & 0.88 & 0.74 & 0.91 \\
\hline 462.14 & $3 s-3 p$ & ${ }^{3} \mathrm{P}^{0}-{ }^{3} \mathrm{P}$ & $1-0$ & 0.882 & 8 & 0.92 & 0.80 & 0.95 \\
\hline 463.05 & $3 s-3 p$ & ${ }^{3} \mathrm{P}^{0}-{ }^{3} \mathrm{P}$ & $2-2$ & 0.775 & 7 & 1.00 & 0.88 & 1.12 \\
\hline 464.31 & $3 s-3 p$ & ${ }^{3} \mathrm{P}^{0}-{ }^{3} \mathrm{P}$ & $2-1$ & 0.477 & 7 & 1.06 & 0.94 & 1.25 \\
\hline 465.45 & $3 s-3 p$ & ${ }^{1} \mathrm{P}^{0}-{ }^{3} \mathrm{P}$ & $1-2$ & 0.022 & 11 & 0.92 & 0.82 & \\
\hline 469.46 & $3 d-4 f$ & ${ }^{1} \mathrm{P}^{0}-\mathrm{D}(5 / 2)$ & $1-2$ & 0.607 & 12 & & & \\
\hline 471.84 & $3 p-3 d$ & ${ }^{5} \mathrm{D}^{0}-{ }^{5} \mathrm{D}$ & $4-4$ & 0.295 & 4 & 0.98 & & \\
\hline 472.16 & $3 p-3 d$ & ${ }^{5} \mathrm{D}^{0}-{ }^{5} \mathrm{D}$ & $4-3$ & 0.110 & 11 & 1.41 & & \\
\hline 477.42 & $3 p-3 d$ & ${ }^{3} \mathrm{D}-{ }^{3} \mathrm{D}^{0}$ & $1-2$ & 0.032 & 11 & 1.00 & 0.82 & 0.80 \\
\hline 477.97 & $3 p-3 d$ & ${ }^{3} \mathrm{D}-{ }^{3} \mathrm{D}^{0}$ & $1-1$ & 0.248 & 6 & 0.98 & 1.06 & 0.91 \\
\hline 478.12 & $3 p-3 d$ & ${ }^{3} \mathrm{D}-{ }^{3} \mathrm{D}^{0}$ & $2-3$ & 0.021 & 12 & 1.00 & 0.84 & 0.70 \\
\hline 478.81 & $3 p-3 d$ & ${ }^{3} \mathrm{D}-{ }^{3} \mathrm{D}^{0}$ & $2-2$ & 0.250 & 5 & 0.99 & 0.97 & 1.00 \\
\hline 479.37 & $3 p-3 d$ & ${ }^{3} \mathrm{D}-{ }^{3} \mathrm{D}^{0}$ & $2-1$ & 0.090 & 5 & 1.15 & 1.06 & 1.00 \\
\hline 480.33 & $3 p-3 d$ & ${ }^{3} \mathrm{D}-{ }^{3} \mathrm{D}^{0}$ & $3-3$ & 0.349 & 4 & 1.10 & 1.02 & 1.09 \\
\hline 481.03 & $3 p-3 d$ & ${ }^{3} \mathrm{D}-{ }^{3} \mathrm{D}^{0}$ & $3-2$ & 0.056 & 14 & 1.17 & 1.02 & 1.00 \\
\hline 486.02 & $3 p-3 d$ & ${ }^{3} \mathrm{D}-{ }^{1} \mathrm{D}^{0}$ & $1-2$ & 0.017 & 5 & 1.06 & & \\
\hline 489.51 & $2 p^{3}-3 p$ & ${ }^{1} \mathrm{D}^{0}-{ }^{1} \mathrm{P}$ & $2-1$ & 0.044 & 15 & 1.02 & & \\
\hline
\end{tabular}


Table 2. Continued from Table 1

\begin{tabular}{|c|c|c|c|c|c|c|c|c|}
\hline $\begin{array}{l}\lambda \\
(\mathrm{nm})\end{array}$ & Transition & Multiplet & $J_{i}-J_{k}$ & $\begin{array}{l}A_{k i} \\
\text { This work }\end{array}$ & $\begin{array}{l}\sigma \\
(\%)\end{array}$ & $\begin{array}{l}T w / N I S T \\
\text { ratio }\end{array}$ & $\begin{array}{l}\text { Tw/Musielok } \\
\text { ratio }\end{array}$ & $\begin{array}{l}T w / R Q D O \\
\text { ratio }\end{array}$ \\
\hline 498.74 & $3 p-3 d$ & ${ }^{3} \mathrm{~S}-{ }^{3} \mathrm{P}^{0}$ & $1-0$ & 0.586 & 13 & 0.78 & 0.78 & \\
\hline 499.12 & $3 s-3 p$ & ${ }^{5} \mathrm{P}-{ }^{5} \mathrm{P}^{0}$ & $1-2$ & 0.325 & 35 & 0.92 & & \\
\hline 499.44 & $3 p-3 d$ & ${ }^{3} \mathrm{~S}-{ }^{3} \mathrm{P}^{0}$ & $1-1$ & 0.738 & 5 & 0.97 & 0.96 & 0.98 \\
\hline 500.51 & $3 s-3 p$ & ${ }^{5} \mathrm{P}-{ }^{5} \mathrm{P}^{0}$ & $2-2$ & 1.220 & 7 & 1.05 & 0.95 & 0.97 \\
\hline 500.73 & $3 p-3 d$ & ${ }^{3} \mathrm{~S}-{ }^{3} \mathrm{P}^{0}$ & $1-2$ & 0.844 & 8 & 1.07 & 1.08 & 1.13 \\
\hline 501.64 & $3 p-3 d$ & ${ }^{3} \mathrm{D}-{ }^{3} \mathrm{~F}^{0}$ & $2-2$ & 0.186 & 5 & 1.15 & 1.01 & 0.96 \\
\hline 502.30 & $3 s-3 p$ & ${ }^{5} \mathrm{P}-{ }^{5} \mathrm{P}^{0}$ & $3-2$ & 0.359 & 15 & 0.99 & & \\
\hline 502.57 & $3 p-3 d$ & ${ }^{3} \mathrm{D}-{ }^{3} \mathrm{~F}^{0}$ & $3-3$ & 0.118 & 11 & 1.10 & 1.01 & 1.15 \\
\hline 504.51 & $3 s-3 p$ & ${ }^{3} \mathrm{P}^{0}-{ }^{3} \mathrm{~S}$ & $2-1$ & 0.369 & 8 & 1.08 & 1.11 & 0.98 \\
\hline 507.36 & $3 s-3 p$ & ${ }^{1} \mathrm{P}^{0}-{ }^{3} \mathrm{~S}$ & $1-1$ & 0.029 & 7 & 1.12 & 1.07 & \\
\hline 518.32 & $3 p-3 d$ & ${ }^{5} \mathrm{P}^{0}-{ }^{5} \mathrm{D}$ & $3-3$ & 0.335 & 30 & 1.16 & & \\
\hline 519.04 & $3 p-3 d$ & ${ }^{5} \mathrm{D}^{0}-{ }^{5} \mathrm{~F}$ & $4-4$ & 0.156 & 16 & 0.88 & & \\
\hline 531.34 & $3 p-3 d$ & ${ }^{5} \mathrm{P}^{0}-{ }^{5} \mathrm{P}$ & $1-1$ & 0.147 & 8 & 1.04 & & \\
\hline 532.02 & $3 p-3 d$ & ${ }^{5} \mathrm{P}^{0}-{ }^{5} \mathrm{P}$ & $2-1$ & 0.382 & 15 & 0.91 & & \\
\hline 532.10 & $3 p-3 d$ & ${ }^{5} \mathrm{P}^{0}-{ }^{5} \mathrm{P}$ & $1-2$ & 0.274 & 11 & 1.09 & & \\
\hline 533.87 & $3 p-3 d$ & ${ }^{5} \mathrm{P}^{0}-{ }^{5} \mathrm{P}$ & $2-3$ & 0.260 & 13 & 1.41 & & \\
\hline 534.02 & $3 p-3 d$ & ${ }^{5} \mathrm{P}^{0}-{ }^{5} \mathrm{P}$ & $3-2$ & 0.200 & 21 & 0.77 & & \\
\hline 535.12 & $3 p-3 d$ & ${ }^{5} \mathrm{P}^{0}-{ }^{5} \mathrm{P}$ & $3-3$ & 0.317 & 19 & 0.86 & & \\
\hline 545.21 & $3 p-3 d$ & ${ }^{3} \mathrm{P}-{ }^{3} \mathrm{P}^{0}$ & $0-1$ & 0.087 & 12 & 0.98 & 1.09 & 0.78 \\
\hline 545.42 & $3 p-3 d$ & ${ }^{3} \mathrm{P}-{ }^{3} \mathrm{P}^{0}$ & $1-0$ & 0.302 & 6 & 0.90 & 0.98 & 0.90 \\
\hline 546.26 & $3 p-3 d$ & ${ }^{3} \mathrm{P}-{ }^{3} \mathrm{P}^{0}$ & $1-1$ & 0.103 & 6 & 1.03 & 1.08 & 1.23 \\
\hline 547.53 & $3 s-4 p$ & ${ }^{1} \mathrm{D}^{0}-{ }^{1} \mathrm{D}$ & $2-2$ & 0.047 & 32 & 1.00 & & \\
\hline 547.81 & $3 p-3 d$ & ${ }^{3} \mathrm{P}-{ }^{3} \mathrm{P}^{0}$ & $1-2$ & 0.052 & 11 & 1.08 & 1.11 & 0.63 \\
\hline 548.01 & $3 p-3 d$ & ${ }^{3} \mathrm{P}-{ }^{3} \mathrm{P}^{0}$ & $2-1$ & 0.141 & 7 & 1.09 & 1.24 & 1.01 \\
\hline 549.57 & $3 p-3 d$ & ${ }^{3} \mathrm{P}-{ }^{3} \mathrm{P}^{0}$ & $2-2$ & 0.262 & 5 & 1.09 & 1.16 & 1.06 \\
\hline 552.62 & $3 s-3 p$ & ${ }^{5} \mathrm{P}-{ }^{5} \mathrm{D}^{0}$ & $1-2$ & 0.179 & 13 & 0.84 & & \\
\hline 553.02 & $3 s-3 p$ & ${ }^{5} \mathrm{P}-{ }^{5} \mathrm{D}^{0}$ & $2-3$ & 0.356 & 18 & 0.88 & & \\
\hline 554.01 & $3 s-3 p$ & ${ }^{5} \mathrm{P}-{ }^{5} \mathrm{D}^{0}$ & $1-2$ & 0.745 & 19 & 1.24 & & \\
\hline 554.35 & $3 s-3 p$ & ${ }^{5} \mathrm{P}-{ }^{5} \mathrm{D}^{0}$ & $2-2$ & 0.340 & 11 & 0.97 & & \\
\hline 566.66 & $3 s-3 p$ & ${ }^{3} \mathrm{P}^{0}-{ }^{3} \mathrm{D}$ & $1-2$ & 0.327 & 10 & 0.87 & 1.00 & 0.91 \\
\hline 567.60 & $3 s-3 p$ & ${ }^{3} \mathrm{P}^{0}-{ }^{3} \mathrm{D}$ & $0-1$ & 0.304 & 6 & 1.03 & 1.13 & 1.15 \\
\hline 567.96 & $3 s-3 p$ & ${ }^{3} \mathrm{P}^{0}-{ }^{3} \mathrm{D}$ & $2-3$ & 0.492 & 9 & 0.94 & 1.02 & 1.04 \\
\hline 568.62 & $3 s-3 p$ & ${ }^{3} \mathrm{P}^{0}-{ }^{3} \mathrm{D}$ & $1-1$ & 0.215 & 10 & 1.11 & 1.21 & 1.09 \\
\hline 571.08 & $3 s-3 p$ & ${ }^{3} \mathrm{P}^{0}-{ }^{3} \mathrm{D}$ & $2-2$ & 0.140 & 10 & 1.13 & 1.23 & 1.19 \\
\hline 573.07 & $3 s-3 p$ & ${ }^{3} \mathrm{P}^{0}-{ }^{3} \mathrm{D}$ & $2-1$ & 0.018 & 12 & 1.39 & 1.29 & 1.39 \\
\hline 592.78 & $3 p-3 d$ & ${ }^{3} \mathrm{P}-{ }^{3} \mathrm{D}^{0}$ & $0-1$ & 0.346 & 3 & 1.08 & 1.23 & 1.33 \\
\hline 593.18 & $3 p-3 d$ & ${ }^{3} \mathrm{P}-{ }^{3} \mathrm{D}^{0}$ & $1-2$ & 0.473 & 4 & 1.11 & 1.33 & 1.34 \\
\hline 594.02 & $3 p-3 d$ & ${ }^{3} \mathrm{P}-{ }^{3} \mathrm{D}^{0}$ & $1-1$ & 0.289 & 7 & 1.28 & 1.74 & 1.48 \\
\hline 594.17 & $3 p-3 d$ & ${ }^{3} \mathrm{P}-{ }^{3} \mathrm{D}^{0}$ & $2-3$ & 0.659 & 5 & 1.19 & 1.41 & 1.41 \\
\hline 595.24 & $3 p-3 d$ & ${ }^{3} \mathrm{P}-{ }^{3} \mathrm{D}^{0}$ & $2-2$ & 0.147 & 5 & 1.16 & 1.47 & 1.27 \\
\hline 595.43 & $3 d-4 p$ & ${ }^{1} \mathrm{P}^{0}-{ }^{1} \mathrm{~S}$ & $1-0$ & 0.508 & 14 & 1.03 & & \\
\hline 615.08 & $3 d-4 p$ & ${ }^{3} \mathrm{~F}^{0}-{ }^{3} \mathrm{D}$ & $2-2$ & 0.026 & 4 & 0.90 & & \\
\hline 616.78 & $3 d-4 p$ & ${ }^{3} \mathrm{~F}^{0}-{ }^{3} \mathrm{D}$ & $4-3$ & 0.311 & 9 & 1.17 & & \\
\hline 617.02 & $3 d-4 p$ & ${ }^{3} \mathrm{~F}^{0}-{ }^{3} \mathrm{D}$ & $2-1$ & 0.288 & 14 & 1.01 & & \\
\hline 617.33 & $3 d-4 p$ & ${ }^{3} \mathrm{~F}^{0}-{ }^{3} \mathrm{D}$ & $3-2$ & 0.345 & 12 & 1.32 & & \\
\hline 634.06 & $3 d-4 p$ & ${ }^{3} \mathrm{D}^{0}-{ }^{3} \mathrm{P}$ & $3-2$ & 0.199 & 16 & 0.93 & & \\
\hline 634.69 & $3 d-4 p$ & ${ }^{3} \mathrm{D}^{0}-{ }^{3} \mathrm{P}$ & $1-1$ & 0.067 & 20 & 0.97 & & \\
\hline 637.96 & $3 s-3 p$ & ${ }^{3} \mathrm{P}^{0}-{ }^{1} \mathrm{P}$ & $1-1$ & 0.049 & 10 & 0.80 & 0.80 & \\
\hline 648.21 & $3 s-3 p$ & ${ }^{1} \mathrm{P}^{0}-{ }^{1} \mathrm{P}$ & $1-1$ & 0.333 & 7 & 1.11 & & 1.03 \\
\hline 650.46 & $3 d-4 p$ & ${ }^{3} \mathrm{D}^{0}-{ }^{3} \mathrm{D}$ & $3-3$ & 0.062 & 10 & 1.17 & & \\
\hline 661.06 & $3 p-3 d$ & ${ }^{1} \mathrm{D}-{ }^{1} \mathrm{~F}^{0}$ & $2-3$ & 0.647 & 10 & 1.02 & & 1.01 \\
\hline 661.36 & $4 s-3 s$ & ${ }^{3} \mathrm{P}^{0}-{ }^{3} \mathrm{P}$ & $2-2$ & 0.219 & 34 & 1.39 & & \\
\hline 662.98 & $3 d-4 p$ & ${ }^{1} \mathrm{D}^{0}-{ }^{1} \mathrm{P}$ & $2-1$ & 0.291 & 19 & 1.08 & & \\
\hline 663.48 & $4 s-3 s$ & ${ }^{3} \mathrm{P}^{0}-{ }^{3} \mathrm{P}$ & $2-1$ & 0.091 & 10 & 1.03 & & \\
\hline 681.00 & $3 d-4 p$ & ${ }^{3} \mathrm{P}^{0}-{ }^{3} \mathrm{~S}$ & $2-1$ & 0.231 & 6 & 1.00 & & \\
\hline 683.41 & $3 d-4 p$ & ${ }^{3} \mathrm{P}^{0}-{ }^{3} \mathrm{~S}$ & $1-1$ & 0.158 & 21 & 0.97 & & \\
\hline
\end{tabular}

